\title{
A DESIGN OF WIDE BAND ANTENNA FOR AUTOMOTIVE APPLICATION
}

\section{C.GANAVEL}

Assistant Professor, EEE Marine, Amet University, Chennai, India

ABSTRACT
This paper proposes a wide band fix radio wire for vehicle correspondence. The plan prerequisites are to meet
the frequencies of 3.5-5.5 GHz groups. The proposed reception apparatus comprises of a half circle fix implanted with
line resonators keeping in mind the end goal to accomplish wide band reverberation. The half circle fix produces
extensive variety of reverberating frequencies to cover3.5 GHz WiMax band, 3.7-4.2 GHz S-band and $5.2 \mathrm{GHz}$ WLAN
band. Line resonators are upgraded to accomplish appropriate wide band operation of the reception apparatus.
The proposed radio wire is sustained by utilizing a 50 ohm Microstrip line. The reenacted brings about terms of return
misfortune; show the appropriateness of the radio wire for vehicle correspondence. The planned reception apparatus is
reenacted utilizing Advanced Design Systems (ADS).
KEYWORDS: Half Circle Fix; Line Resonators; Microstrip; Vehicle Correspondence; ADS

Received: Oct 06, 2017; Accepted: Oct 26, 2017; Published: Jan 30, 2018; Paper Id.: IJMPERDFEB201895

\section{INTRODUCTION}

Receiving wires get electromagnetic waves and pass them into a collector or they transmit electromagnetic waves which have been created by [Ray, 2007] a transmitter. Utilized radio wires for car applications are helical receiving wires, monopole reception apparatuses and microstrip radio wires., FM/AM, GPS, satellite radio, remote keyless section, remote begin motor, tire weight sensor, car radar etc. For previously mentioned administrations require Special reception apparatus with the unique plan, so it is not plausible to utilize isolate receiving wire for every so multiband radio wire framework is achievable [Wong, 2008]. There are distinctive sorts of multiband radio wire which can be classed as: Printed dipole, circle reception apparatus, space receiving wire and printed transformed f receiving wire (PIFA). Keeping in mind the end goal to kill Line of Sight issue in multiband reception apparatus we proceed onward to differing qualities procedure (space/spatial assorted qualities) [Hong, 2008].

Lately, we invested increasingly energy in our autos. Sol it wound up noticeably clear to actualize autostimulation frameworks into the auto for solace and driver data.[ Wong,2008] Auto diversion started with AMgathering on short wave groups. Impact of parameter variations on the steady-state behaviour of grid-connected renewable energy conversion systems. FM-tuners on VHF groups took after soon, with stereo sound, tape players and CD-players to engage travellers. For driver data, present-day route frameworks not just locate the most proficient course, additionally give a diagram of activity circumstance.

SDARS which is predominantly for satellite TVs, mobile phones, WiMAX and GPS is presently a standout amongst the most famous field of inquires about for proficient auto data frameworks. In present-day autos, we find up to 24 receiving wires set on the vehicle and inside the vehicle and the vehicle. In the following 
years, the number will increase even ascent. To outline a vehicular radio wire the necessities are set, then the area is looked and the best receiving wire innovation is chosen.

In this paper, a conservative wide band radio wire for car applications is proposed. The wide band recurrence qualities are acquired by implanting a half circle fix and line resonators. Audited articles, Synthesis, growth and characterization of novel semi-organic nonlinear optical potassium boro-succinate (KBS) single crystals. Low-temperature method for synthesis of $\mathrm{ZnS}$ quantum dots and its luminescence characterization studies. Impact of parameter variations on the steady-state behaviour of grid-connected renewable energy conversion systems.

\section{WIDE BAND ANTENNA DESIGN}

\section{Development of Proposed Antenna}

The development of the proposed receiving wire is portrayed in Figure. 1. At initial, a half circle fix is implanted with a line resonator as appeared in Figure. 1(a) is intended to work at the higher resounding recurrence with poor coordinating. To this principal reception apparatus, a different line resonator as in Figure. 1(b) is added to energize the recurrence groups for car application. In this way, a wide band resonator is accomplished utilizing the line resonator arrangement.
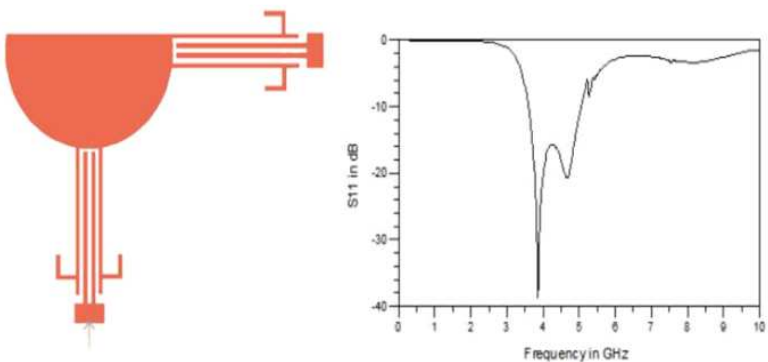

Figure 1(a): Layout of Antenna with Simulated S11 Result
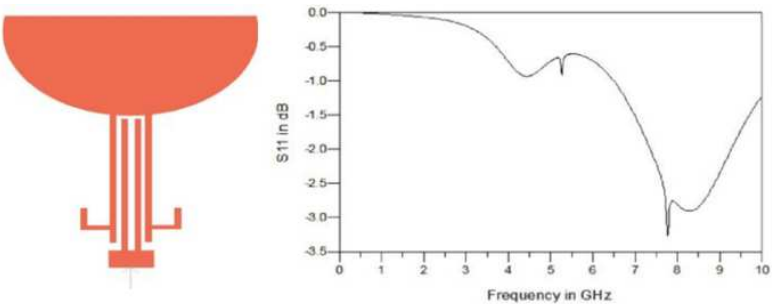

Figure 1(b): Layout of the Antenna with Simulated S11 Result
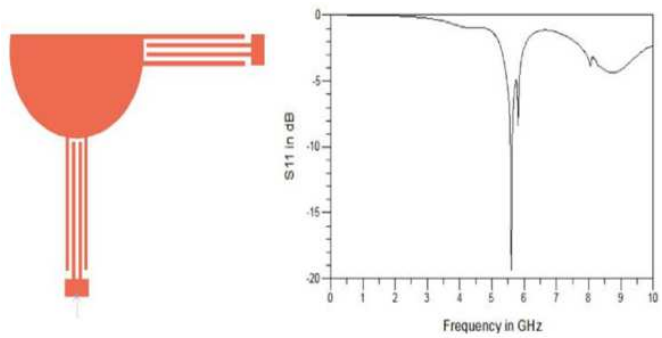

Figure 1(c): Design of the Radio wire with Recreated S11 Result

The outlined reception apparatus needs enhancement. On this thought, the L stubs are included two sides of the line resonators to make the radio wire reverberates in the coveted wide band go as in Figure. 1(c). 


\section{Wide Band Antenna Design}

Figure 2 Demonstrates the geometry of the proposed wide band radio wire which possesses a volume of $13.7 \mathrm{x}$ $14.964 \times 1.6 \mathrm{~mm}$

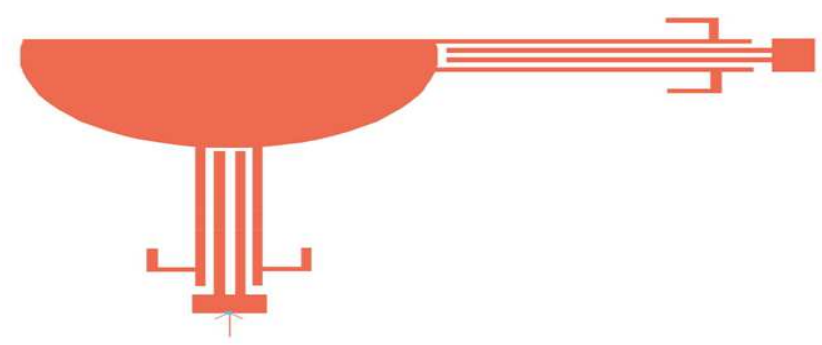

(A)

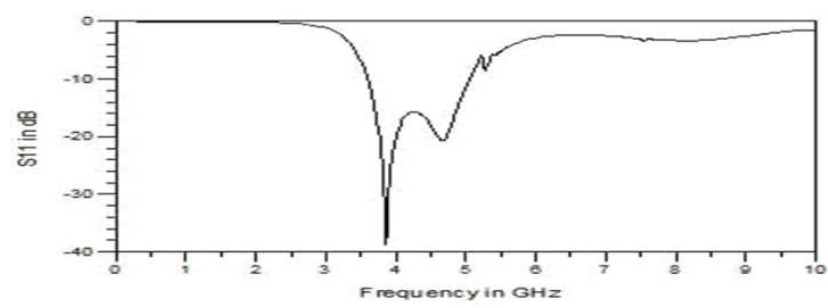

(B)

Figure 2: Format of the Proposed Recieving Wire (An) and its Recreated S11 Result (B)

The Primary recieving wire works in higher band of recurrence. The Secondary radio wire works in wide band which related car application. The tertiary reception apparatus joined with $\mathrm{L}$ stubs resounds at the recurrence band of 3.55.5GHz. Radio wire with discontinuities in essential and optional reception apparatus works likewise at three distinctive recurrence groups. Proposed wide band reception apparatus with line resonator works at three diverse recurrences relating three applications like $\mathrm{C}$ band, WLAN and WiMAX. The VANET Network based on the packet switching is presented in [Sindhuja, 2015].

The edge-to-edge separating is picked compared to the wavelength of most reduced resounding recurrence. The recieving wire components are situated in such an approach to get orthogonal polarizations. Advance the replication of on a level plane and vertically energized recieving wire unit cells produces corresponding radiation design along E plane and $\mathrm{H}$ plane. Hence the recieving wire scope and information quality are enhanced amid versatility without influencing the feel of the vehicle. The measured S-parameter normal for the proposed reception apparatus appears in Figure. 2(b). A portion of the variables that gauge the differing qualities execution has been assessed.

Table 1: Tabulation for Simulated Frequencies

\begin{tabular}{|l|c|}
\hline APPLICATION & SIMULATED \\
\hline W-LAN & 5.2 \\
\hline S-BAND & $3.7-4.2$ \\
\hline Wi-Max & 3.5 \\
\hline
\end{tabular}

The Figure. 3. and Figure 4 Demonstrates the 3D radiation example, pick up and directivity of wide band radio wire. The radiation example is directional. With the directional radio wires, you can occupy the RF vitality in a specific bearing to more distant separations. In this way, you can cover long ranges. However the viable shaft width 
diminishes. This kind of recieving wire is useful in close LOS scope, for example, covering lobbies, long passages, isle structures with spaces in the middle of, and so on. In any case, as the rakish scope is less, you can't cover vast territories. This is a weakness for general indoor scope since you might want to cover a more extensive rakish range around the AP

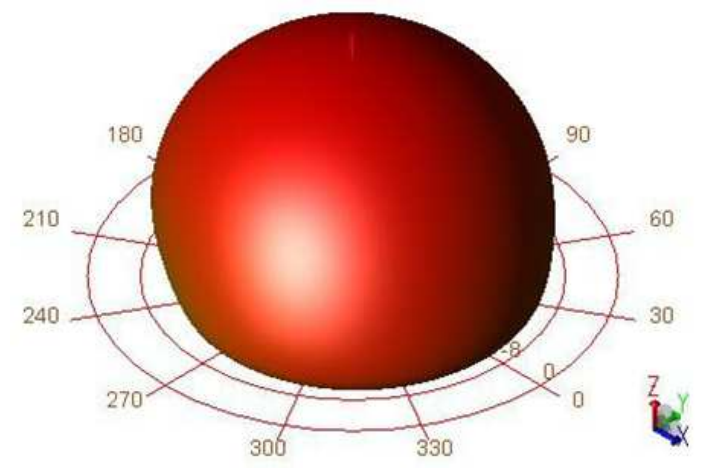

Figure 3: Radiation Pattern

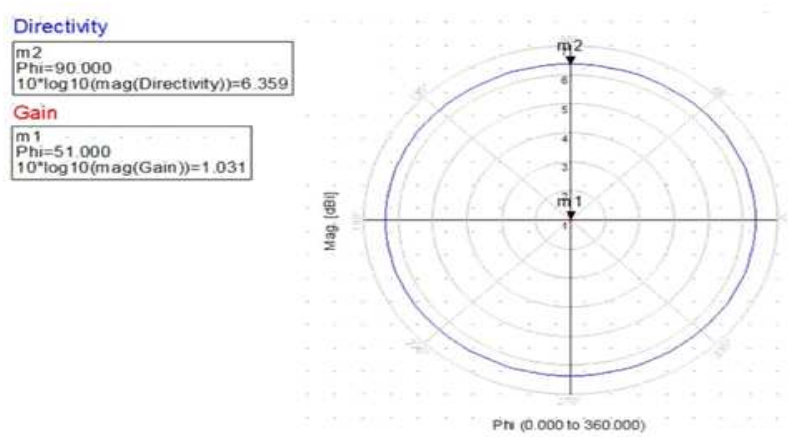

Figure 4: Gain and Directivity of Wide Band Patch Antenna

\section{CONCLUSIONS}

The Wide Band Antenna for Automotive Application has been presented. Folded microstrip line and line resonator concept are exploited to achieve a compact wide band antenna. The semicircular patch generates wide range of resonating frequencies to cover 3.5 GHz WiMax band, 3.7-4.2 GHz S-band and 5.2 GHz WLAN band is achieved. Future scope is to design for wide band operating antenna for multiple applications by introducing notch bands.

\section{REFERENCES}

1. K. P. Ray, Y. Ranga, and p. Gabhale. (2007) "Printed Square Monopole Antenna with Semicircular Base for Ultra Wide Bandwidth", electronics letters, vol. 43, no. 5, 263 pages.

2. K. L. Wong and C. H. Huang. (July 2008). "Printed Loop Antenna with a Perpendicular Feed for Pentaband Mobile Phone Applications", IEEE Transactions on Antennas and Propagation, vol. 56, 2138-2141.

3. Swapnali Shinde \& R. P. Labade, Design of a Planar Monopole Ultra Wide Band Patch Antenna, International Journal of Electrical and Electronics Engineering Research (IJEEER), Volume 4, Issue 1, January - February 2014, pp. 47-52

4. S. Hong, W.Kim, S. Kahng, and J. Choi. (May 2008). "Design of An Internal Multi resonant Monopole Antenna For GSM900/ DCS1800 / USPCS / S-DMB Operation”, IEEE Transactions On Antennas And Propagation, vol. 56, 1437-1443. 
5. K. L. Wong and C. H. Huang.,(July 2008). "Printed Loop Antenna With a Perpendicular Feed For Pent band Mobile Phone Applications", IEEE Transactions on Antennas and Propagation, vol. 56, 2138- 2141.

6. M.Sinduja, M.Yuvaraju. (2015) Congestion Control Using On-Board Data Units in VANET Scenar IOS.International Journal of MC square Scientific Research (IJMSR).7(1):1-9. 
